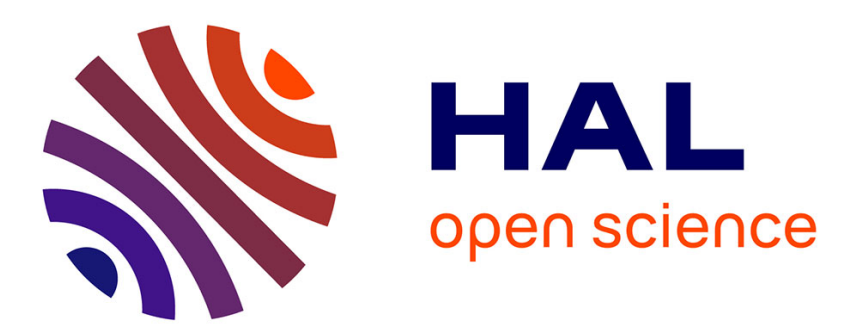

\title{
Real-time monitoring for the morphological variations of single gold nanorods
}

Tao Xie, Chao Jing, Wei Ma, Zhifeng Ding, Andrew James Gross, Yitao Long

\section{To cite this version:}

Tao Xie, Chao Jing, Wei Ma, Zhifeng Ding, Andrew James Gross, et al.. Real-time monitoring for the morphological variations of single gold nanorods. Nanoscale, 2015, 7 (2), pp.511-517. 10.1039/C4NR05080K . hal-03015152

\section{HAL Id: hal-03015152 https://hal.science/hal-03015152}

Submitted on 19 Nov 2020

HAL is a multi-disciplinary open access archive for the deposit and dissemination of scientific research documents, whether they are published or not. The documents may come from teaching and research institutions in France or abroad, or from public or private research centers.
L'archive ouverte pluridisciplinaire HAL, est destinée au dépôt et à la diffusion de documents scientifiques de niveau recherche, publiés ou non, émanant des établissements d'enseignement et de recherche français ou étrangers, des laboratoires publics ou privés. 

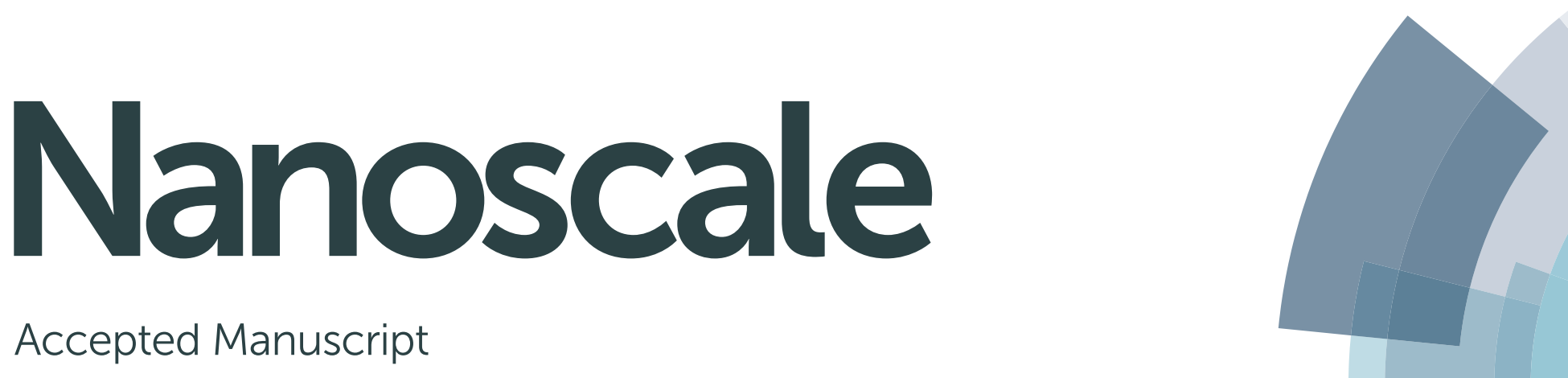

\section{Accepted Manuscript}

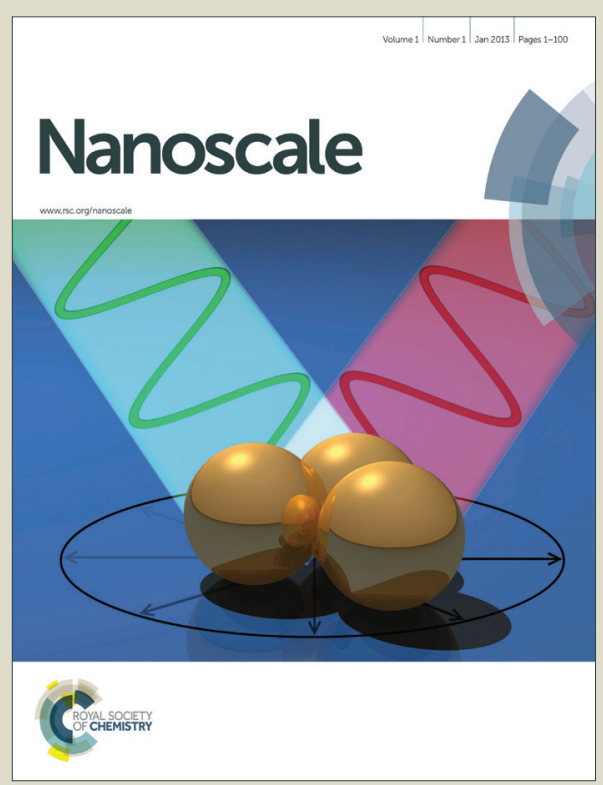

This is an Accepted Manuscript, which has been through the Royal Society of Chemistry peer review process and has been accepted for publication.

Accepted Manuscripts are published online shortly after acceptance, before technical editing, formatting and proof reading. Using this free service, authors can make their results available to the community, in citable form, before we publish the edited article. We will replace this Accepted Manuscript with the edited and formatted Advance Article as soon as it is available.

You can find more information about Accepted Manuscripts in the Information for Authors.

Please note that technical editing may introduce minor changes to the text and/or graphics, which may alter content. The journal's standard Terms \& Conditions and the Ethical guidelines still apply. In no event shall the Royal Society of Chemistry be held responsible for any errors or omissions in this Accepted Manuscript or any consequences arising from the use of any information it contains. 


\title{
ARTICLE
}

Cite this: DOI: $10.1039 /$ xoxxooooox

\section{A Real-Time Monitoring for the Morphological Variations of Single Gold Nanorods $\uparrow$}

\author{
Tao Xie, ${ }^{a}$ Chao Jing, ${ }^{a}$ Wei Ma, ${ }^{a}$ Zhifeng Ding, ${ }^{\mathrm{b}}$ Andrew James Gross ${ }^{\mathrm{c}}$ and Yi-Tao \\ Long*a
}

Received ooth January 2012 Accepted ooth January 2012

DOI: 10.1039/xoxxooooox

www.rsc.org/nanoscale
The morphological characteristics of metal nanoparticles, particularly the shape, play an essential role in the optical, physical and chemical properties. In this work, we reported a transverse etching process to investigate the morphological variations of single gold nanorods (GNRs). Dark-field microscopy and Rayleigh scattering spectroscopy were used as complementary technologies to track the transverse etching process. Dark-field imaging with high spatial and temporal resolution could easily monitor the transverse etching process of GNRs in situ and in real time. Interactions between the scattering spectrum and the morphological variations were judiciously calculated within the dipole approximation by Drude function. The calculated peak shift of GNRs $\left(\Delta \lambda_{\max }=17 \mathrm{~nm}\right)$ was obtained via the ratio of long axis and short axis (aspect ratio) of GNRs from transmission electron microscope. The average scattering peak shift $\left(\Delta \lambda_{\max }=22 \mathrm{~nm}\right)$ from Rayleigh scattering spectroscopy was in good agreement with the calculated peak shift. Monitoring the morphological variations of single GNRs enables us to track the transverse etching of GNRs under arbitrary time. This promises to be a useful method for the study of different nanomaterials and their spectral properties.

\section{Introduction}

Anisotropic noble metal nanoparticles have attracted a great deal of attention due to their special optical properties, in comparison to noble spherical nanoparticles. Of particular interest is the applications of octahedron, ${ }^{1}$ cube, ${ }^{2}$ bitetrahedra ${ }^{3}$ and dumbbell morphologies. ${ }^{4}$ In order to know the mechanism of the special optical characteristics of these nanostructures, ${ }^{5-12}$ it is important to develop selective methods to control the size and shape. . $^{3,13,14}$

Here, the scattering peak of single gold nanorods (GNRs) is obtained. And it is an important feature of GNRs which depends on small variations in the aspect ratio. Recent reports have focused on methods to change the long axis of gold nanorods, to reflect the change in aspect ratio, for instance, by seed-mediated growth in the presence of iodide ions. ${ }^{4}$ Morphological control in the middle section of GNRs to obtain gold nanodumbbells is rarely investigated via etching methods. It is acknowledged in literature that additives, most commonly halide ions, cationic surfactants and amino acids, play a key role in directing the growth of anisotropic nanostructures. ${ }^{15-22}$
Chlorauric acid $\left(\mathrm{HAuCl}_{4}\right)$ is a common oxidizing agent used in thermal seed-mediated synthesis as a means of inducing the growth of gold nanorods. ${ }^{23-25}$ However, $\mathrm{HAuCl}_{4}$ can also bind to cetyltrimethylammonium bromide (CTAB) micelles, drastically altering the effect of $\mathrm{HAuCl}_{4}$, in which enable gold nanoparticles to dissolve. ${ }^{26}$ It is not clear whether the chloride ions from $\mathrm{HAuCl}_{4}$ are exchanged with the bromide ions from CTAB or whether micellisation of the gold salt contributes to the electron transfer. A number of diverse and conflicting theories exist to explain the roles of CTAB with bromide anions. The most popular explanation for the role of CTAB with bromide anions is that they bind to the gold $\{100\}$ surface, stabilizing the surface and therefore slowing the gold reaction at the site. ${ }^{24,27-29}$ In spite of this well-known explanation, some research efforts have proposed that the micelles solution of CTAB with bromide anions prefer to bind $\{110\}$ or $\{111\}$ surfaces selectively, ${ }^{18}, 19,23$ thus forming CTA-Au-Br complexes. $^{20,23,24,30}$ Consequently, there is not a certain conclusion among the proposed mechanisms for the roles of $\mathrm{CTAB}$ and bromide anions on the morphological change in the nanostructure. 
In order to investigate the transverse etching mechanism of GNRs, we use dark-field microscope (DFM) to track the realtime transverse etching process of single GNRs. The localized reaction to induce single GNRs transverse etching is simulated by the Drude function. The average scattering peak shift of GNRs is in good agreement with the calculated peak shift from transmission electron microscope (TEM).

Our strategy for conversion of gold nanorods to gold nanodumbbells by transverse etching is shown (Fig. 1). The CTAB molecular layer first assemble on the transverse side of the gold nanorods. The tips of the gold nanorods are subsequently protected by selective attachment of cysteine. Selective transverse etching is achieved by etching in $\mathrm{HAuCl}_{4}$ solution. The conversion is experimentally characterized using scattering spectroscopy, dark-field microscopy and transmission electron microscopy.

\section{Figure 1 is inserted here}

Fig. 1 Transverse etching reaction on the single particle level. (i) Diagram of GNRs before reaction. Diagram, TEM image, dark-field image and scattering spectra of GNRs in the solution of $0.1 \mathrm{mM}$ cysteine before (ii) and after (iii) adding micellar solution of CTAB and $\mathrm{HAuCl}_{4}$.

\section{Results and discussion}

\section{Characterizations of gold nanorods and gold nanodumbbells}

In the initial experiment, UV-vis spectroscopy was performed on the as-received gold nanorods solution to characterize the plasmon resonance peak. The spectra obtained showed that the gold nanorods possessed two plasmon absorption bands (Fig. $\mathrm{S} 1$ of the ESI $\dagger$ ). Relatively narrow short axis (the minimum length of particle) and long axis (the maximum length of particle) distributions were observed, the $\lambda_{\max }$ at $531 \mathrm{~nm}$ and $650 \mathrm{~nm}$ were attributed to the transverse plasmon resonance peak and the longitudinal plasmon resonance peak, respectively.

Dark-field color images and scattering spectra were recorded at $10 \mathrm{~min}$ intervals between $0 \mathrm{~min}$ and $40 \mathrm{~min}$ during transverse etching of single GNRs to gold nanodumbbells (Fig. 2A). A red shift between 0 and $40 \mathrm{~min}$ was observed in the spectra due to a change in the plasmon resonance scattering behaviour as the morphology of the nanoparticles changed over time. Dark-field images recorded at 0 (Fig. 2A, i) and $40 \mathrm{~min}$ (Fig. 2A, ii) revealed a colour change from orange to red. The change in the peak maximum wavelength was initially very large over the first $20 \mathrm{~min}$ (Fig. 2B). The change in peak maximum subsequently decreased between 30 and $50 \mathrm{~min}$. These changes were consistent with an initial fast transformation period followed by a slower period of morphological variations. TEM images revealed that the etching process in micellar solution for $20 \mathrm{~min}$ (Fig. S2 of the
ESI $\dagger$ ) and 40 min (Fig. 2D) had a similar morphology. These effects might be related to the change in the curvature of the gold nanoparticles. When the Micellar solution reacted, the gold $\{110\}$ surface was solwly changing to $\{111\}$ surface. It caused the curvature in the middle section and the aspect ratio increase. The micellar solution was more difficult to etch when the curvature was high. ${ }^{27}$ The plot (Fig. 2B) also showed that between 30 and $50 \mathrm{~min}$ a greater degree of error in the measured $\Delta \lambda_{\max }$ was observed due to a wider variation in the morphology of the nanoparticles. The larger errors were in part attributed to the decomposition of the $\mathrm{HAuCl}_{4}$ solution. A reaction time of $40 \mathrm{~min}$ in $\mathrm{HAuCl}_{4}$ was chosen because of the significant transformation in optical properties and the smaller variation with repeated measurements.

\section{Figure 2 is inserted here}

Fig. 2 Cysteine-induced transverse etching. (A) Scattering spectra recorded at 0 $\min (0), 10 \mathrm{~min} \mathrm{(O),} 20 \mathrm{~min}(\mathrm{O}), 30 \mathrm{~min}\left(\mathrm{O}^{\circ}\right.$, and $40 \mathrm{~min}(\mathrm{O})$, and corresponding dark-field images recorded at $0 \mathrm{~min}$ (i) and $40 \mathrm{~min}$ (ii) of gold nanorods in 0.1 $\mathrm{mM}$ cysteine containing $1 \mathrm{mM} \mathrm{CTAB}$ and $0.05 \mathrm{mM} \mathrm{HAuCl}_{4}$. (B) The wavelength shift for single GNRs in the presence $(\square)$ and absence $(\Delta)$ of $\mathrm{HAuCl}_{4}$ acid $(0.05$ $\mathrm{mM})$ after $50 \mathrm{~min}$ in the presence of CTAB $(1 \mathrm{mM})$ and cysteine $(0.1 \mathrm{mM})$. Error bars correspond to one standard deviation from the mean point for seven or more independent experiments. TEM images recorded before (C) and after (D) reaction with cysteine then etching in micellar solution. The aspect ratio statistical distribution of the nanoparticles before (E) and after ( $F$ ) the reaction; the measurements were carried out on a minimum of 50 independent particles per sample.

Transmission electron microscopy was used to monitor the size and shape evolution of the nanoparticles before (Fig. 2C) and after (Fig. 2D) the reaction with cysteine and the CTAB$\mathrm{HAuCl}_{4}$ micellar solution. The original GNRs exhibited relatively narrow aspect ratio distributions. After its reaction with $0.1 \mathrm{mM}$ cysteine then the $1 \mathrm{mM}$ CTAB with $0.05 \mathrm{mM}$ $\mathrm{HAuCl}_{4}$ containing solution, the gold nanoparticles had larger aspect ratio distributions. With the middle sections in the transverse direction being recessed, this effect was attributed to the etching reaction occuring at a faster rate in the middle section relative to that at the ends. It was presumably due to the instability of the $\{110\}$ surface of the GNRs. A quantitative analysis of the size distribution of the nanoparticles was also performed using the TEM images (Fig. 2E and 2F). Because of the size difference between the diameter in the middle section and the maximum diameter at the ends, a change in aspect ratio was recorded to compare the relative changes before and after the transverse etching. The original GNRs had a maximum diameter (long axis, $\mathrm{L}_{1}$ ) and a minimum diameter in the middle section (short axis, $\mathrm{L}_{2}$ ) of $100 \pm 3,52.6 \pm 1.7 \mathrm{~nm}$, respectively. During transverse etching, short axis decreased steadily while long axis remained unchanged, indicating that the etching process only took place in the middle section and that the longitudinal reaction was completely blocked. The GNRs had a minimum diameter in the middle section $\left(\mathrm{L}_{3}\right)$ of $47.6 \pm 2.1 \mathrm{~nm}$ after the transverse etching. The associated increase in aspect ratio (from $e_{1}=\mathrm{L}_{1}: \mathrm{L}_{2}=1.9$ to $e_{2}=\mathrm{L}_{1}: \mathrm{L}_{3}=2.1$ ) due to the change in 
morphology was therefore responsible for the red shift observed in the scattering spectra (Fig. 2A). The detailed studies are discussed in the calculation methodology.

\section{CTAB concentration influence on micelle formation}

Surfactant molecules are known to self-assemble into aggregates in aqueous solutions. ${ }^{31}$ In an aqueous solution, single GNRs had previously been encapsulated in a CTAB bilayer. $^{32}$ The result showed a plot of the maximum UV absorbance (Fig. S3 of the ESI $\dagger$ ) recorded of CTAB solutions prepared at varying concentrations. At low concentrations, below the first critical micelle concentration (CMC), the UV spectrum confirmed that the CTAB exhibited a unimolecular structure in solution. ${ }^{31}$ As the concentration of CTAB increased, the micelles gradually associated until the first CMC was reached. The first CMC was estimated to be about $0.8 \mathrm{mM}$ according to the decrease in UV absorbance. The second CMC was reached when the concentration of CTAB exceeded 9.4 $\mathrm{mM}$. These results suggested that the concentration could change the structure of $\mathrm{CTAB}$ in the solution, which might affect the reaction between GNRs and $\mathrm{HAuCl}_{4}$.

\section{Optimum condition for selective protection of GNRs}

In order to optimize the selective protection of the ends of GNRs, dark-field image was performed on gold nanorods before and after the addition of varing concentrations of cysteine and CTAB. Under the suitable concentration of cysteine, it could preferentially modify to the ends of GNRs, which has been proposed by the end-to-end assembly of GNRs using thiol molecules. ${ }^{22,33,34}$ Traces of CTAB is always used as cationic surfactant in aqueous solution of gold nanoparticles. ${ }^{12}$ The mechanism of binding is based on the fact that CTAB bilayer is better ordered on the transverse surface than at the highly curved ends. In other words, the molecules are easily to bind both sides and then the two ends.

The scattering spectra of a single GNR before and after the reaction in varying concentration of cysteine was shown (Fig. $3 \mathrm{~A})$. And the histogram obtained for multiple measurements taken of the maximum scattering peak $\left(\Delta \lambda_{\max }\right)$ value of GNRs was shown (Fig. 3B). The concentraction of cysteine were 0 $\mathrm{mM}, 0.01 \mathrm{mM}, 0.10 \mathrm{mM}$, and $1.00 \mathrm{mM}$. The whole results (Fig. 3) were obtained after adding different concentraction of cysteine and micellar solution in $40 \mathrm{~min}$.

It was found that there exhibited an optimal cysteine concentration of $0.1 \mathrm{mM}$ for inducing the transverse etching while cysteine was completely blocking the end of gold nanorods. When the concentration of cysteine was less than 0.1 $\mathrm{mM}$, cysteine could not block the transverse etching completely. The micellar solution can easily etch both the ends and the middle section of the gold nanorods, causing them to become shorter and smaller. On the other hand, when the concentration of cysteine was larger than $0.1 \mathrm{mM}$, excess cysteine can also deposit in the middle section of GNRs and block the transverse etching. The surface of gold nanorods was protected by the cysteine. The minimum scattering peak redshifted was observed at the concentraction of cysteine $(1 \mathrm{mM})$ which showed the highest aspect ratio. Even micellar solution was the most suitable concentration $(1.00 \mathrm{mM})$, the scattering peak of GNR remained the same.

The influence of CTAB on the transverse etching was also investigated. The scattering spectra of a single gold nanorod was shown (Fig. 3C) and the $\Delta \lambda_{\max }$ changes after reaction with different concentration of micellar solution were shown (Fig. 3D). Micellar solution with varying CTAB concentration was added onto the ITO glass slide containing $0.1 \mathrm{mM}$ cysteine. The results (Fig. 3C and 3D) indicated that the concentration of CTAB increased, the maximum plasmon resonance peak showed a red shift, and thereafter, the peak slowly blue shifted. This suggested that the existing morphology of CTAB had changed. The optimization of micelle formation in CTAB$\mathrm{HAuCl}_{4}$ solution showed that it changed from a unimolecule (below $0.8 \mathrm{mM})$, spherical micelle $(0.8 \sim 9.4 \mathrm{mM})$ to a claviform micelle (exceed $9.4 \mathrm{mM}$ ). Hence, when the concentration of CTAB was about $1 \mathrm{mM}$, it formed the spherical micelle as oppose to the latter. Compared with the results from the dark-field image, the spherical micelle which coated $\mathrm{HAuCl}_{4}$ could easily etch GNRs. The spherical micelle drastically altered the value of the equilibrium constant for the conproportionation and enabled single gold nanorods to be quantitatively dissolved by chlorauric acid. ${ }^{27}$

Glutathione (GSH) could also induce the transverse etching (Fig. S4 of the ESI $\dagger$ ) and that the optimal GSH concentration for a complete blocking of the longitudinal change was also about $0.1 \mathrm{mM}$ (Fig. S5 of the ESI $\dagger$ ). The transverse etching performed in the presence of GSH suggested that GSH contained both carboxyl and amino groups can selectively block the GNRs (Fig. 3E). GSH and cysteine were present in the zwitterionic form in the acid micellar solution. On the other hand, the sole transverse etching was not observed for mercaptoethylamine (Fig. 3F), although mercaptoethylamine also contained a thiol group. The transverse etching was also not observed for 11-mercaptoundecanoic acid (MUA). ${ }^{22}$ The experimental results of MUA suggested that only cysteine and GSH, keeping the zwitterionic groups could block the ends over GNRs. The compounds that only had carboxyl or amino groups did not obtain the same results as cysteine and GSH.

\section{Figure 3 is inserted here}

Fig. 3 The scattering peak shift of single gold nanoparticle (A) and the maximum scattering peak of gold nanoparticles (B) before (-) and after addition cysteine solution at $0 \mathrm{mM}(-), 0.01 \mathrm{mM}(-), 0.1 \mathrm{mM}(-)$, and $1 \mathrm{mM}(-)$ after $40 \mathrm{~min}$ reaction in micellar solution. The scattering peak shift of single gold nanoparticle (C) and the maximum scattering peak of gold nanoparticles (D) contain $0.10 \mathrm{mM}$ cysteine (-) and then add CTAB-HAuCl${ }_{4}$ micellar solution at $0.01 \mathrm{mM}(-), 1.00 \mathrm{mM}$ $(-), 10.0 \mathrm{mM}(-)$, and $100 \mathrm{mM}(-)$ after $40 \mathrm{~min}$. Time-dependent changes in the scattering spectrum of gold nanorods held in $0.1 \mathrm{mM} \mathrm{GSH}(\mathrm{E})$ and $0.1 \mathrm{mM}$ mercaptoethylamine (F) solution containing $1 \mathrm{mM} \mathrm{CTAB}$ and $0.05 \mathrm{mM} \mathrm{HAuCl}_{4}$ at $0 \mathrm{~min}(-), 10 \mathrm{~min}(-), 20 \mathrm{~min}(-), 30 \mathrm{~min}(-)$, and $40 \mathrm{~min}(-)$. Error bars represented the standard deviations for measurements taken from at least ten independent experiments. 


\section{Calculation methodology of transverse etching}

To quantify the mechanism of these effects, a quasistatic limit approach is utilized to calculate the extinction spectra of dumbbell-like nanoparticles. Prior to derivation, the wavelength of incident light is much longer than the diameter of the particles. Drude function below is all based on this approach unless noted otherwise. In order to calculate the plasmon resonance scattering peak shifts, the change in aspect ratio is needed in the transverse etching. For the GNRs and dumbbelllike nanoparticles are shown (Fig. 2C and 2D), the average size of nanorods is assumed to be two hemispheres and a cylinder. The reaction first takes place in the $\{110\}$ surface, and then turns to $\{111\}$ surface. The volume change could be considered as the cylinder etching into two circular truncated cones and the length of GNRs keep the same. The initial and final morphology of single gold nanoparticle is theoretically simulated (Fig. 4). The detail calculation methodology of this reaction is shown. See ESI†.

\section{Figure 4 is inserted here}

Fig. 4 Simulation process of transverse etching of single GNRs.

The original GNRs had a maximum diameter (long axis, $\mathrm{L}_{1}$ ) and a minimum diameter in the middle section (short axis, $\mathrm{L}_{2}$ ), respectively. The GNRs contained a new minimum diameter in the middle section $\left(\mathrm{L}_{3}\right)$ after the transverse etching. The surface plasmon resonance shift of single dumbbell-like nanoparticles is demonstrated below,

$$
\Delta \lambda=-\frac{\left(e_{2}-e_{1}\right)\left(e_{1}+2 e_{2}\right)\left(e_{1}-1\right)}{2 e_{2}^{2}\left(3 e_{1}-1\right)} \lambda_{p} \sqrt{\varepsilon_{\infty}+\left(\frac{1-L}{L}\right) \varepsilon_{m}}
$$

Where $\varepsilon_{\infty}$ is the high frequency contribution to the metal dielectric function (12.2 for gold $\left.^{35}\right), \varepsilon_{\mathrm{m}}$ is the dielectric constant of the medium, which is $1.77, \lambda_{\mathrm{p}}$ is the bulk plasma wavelength for gold, that is $131 \mathrm{~nm}, \mathrm{~L}$ is the depolarization factor, which is $0.125, e_{1}$ is the aspect ratio before the etching reaction $\left(\mathrm{L}_{1}: \mathrm{L}_{2}\right)$ and $e_{2}$ is the aspect ratio after the etching reaction $\left(\mathrm{L}_{1}: \mathrm{L}_{3}\right)$.

As the etching reaction occurs, the short axis and the volume is altered correspondingly, therefore, the DFM image and scattering peak. The relationship among aspect ratio, volume and simulated scattering peak of GNRs are presented in Table 1. The average values of aspect ratio before and after the transverse etching are 1.9 and 2.1, respectively (Fig. 2). For the average aspect ratio of the nanorods, about $9500 \mathrm{~nm}^{3}$ volume changes could lead to $17 \mathrm{~nm}$ redshifts. Noticeably, a slight change in aspect ratio induces a severe change in the volume and scattering peaks. Therefore, this calculation methodology of converting the morphological variations from aspect ratio into scattering peak could be used to estimate the real-time shape of single nanorods. Thus, the calculation methodology makes it easier and less time-consuming to get the morphological information in comparison to the TEM images.

Table 1. Comparison of the Relationship between the Change in Aspect Ratio $\left(\Delta \mathrm{e}=\mathrm{e}_{2}-\mathrm{e}_{1}\right)$, Volume Changes $(\Delta \mathrm{V})$ and Simulated Scattering Peak $\left(\Delta \lambda_{\max }\right)$ Red-shifted after the Transverse Etching of Single GNRs.

\begin{tabular}{ccccccc} 
No. & 1 & 2 & 3 & 4 & 5 & 6 \\
\hline$\Delta \mathrm{e}^{\mathrm{a}}$ & 0.1 & 0.2 & 0.3 & 0.4 & 0.5 & 0.6 \\
$\Delta \mathrm{V}^{\mathrm{b}}\left(\mathrm{nm}^{3}\right)$ & 5063 & 9499 & 13420 & 17050 & 19971 & 22752 \\
$\Delta \lambda_{\max } \mathrm{c}(\mathrm{nm})$ & 9 & 17 & 24 & 30 & 36 & 41
\end{tabular}

${ }^{\text {a }}$ The changes in aspect ratio of GNRs are measured from their TEM images. ${ }^{\mathrm{b}}$ The volume change is calculated by the morphological variations from GNRs to gold nanodumbbells. ${ }^{\mathrm{c}}$ The scattering peak red-shifted was calculated using equation 1 .

\section{Experimental section}

\section{Materials}

Chlorauric acid $\left(\mathrm{HAuCl}_{4},>99.0 \%\right)$ was obtained from Sigma Aldrich Chemicals Co. (St. Louis, MO, USA). Cetyltrimethylammonium bromide (CTAB, >96\%), L-cysteine ( $>99 \%$ ) and reduced glutathione (GSH, $>99 \%$ ) were obtained from Aladdin Reagent Co. (Shanghai, China). All the chemicals were of analytical grade. Aqueous solutions were prepared using ultrapure water with a resistivity of $18.2 \mathrm{M} \Omega \mathrm{cm}$ obtained from Milli-Q apparatus (China). The indium-tin oxide (ITO) slides were purchased from Geao Co. Ltd. (China). The gold nanorods were purchased from NanoSeedz Ltd. (Hong Kong).

\section{Scattering spectroscopy by dark-field microscopy}

An inverted microscope (Eclipse Ti-U, Nikon, Japan) equipped with a dark-field condenser $(0.8<\mathrm{NA}<0.95)$ and $40 \times$ objective lens (NA $=0.8$ ) was used to observe the nanoparticles in the dark-field. The gold nanoparticles were excited by a white light source (100 W, halogen lamp) and the generated plasmon resonance scattering light. The scattered light of the gold nanoparticles was captured through the objective lens and then split by a monochromator (Acton SP2300i, PI). The monochromator was equipped with a grating (grating density = 300 lines $/ \mathrm{mm}$; wavelength $=500 \mathrm{~nm}$ ) and recorded by a spectrometer CCD (PIXIS 400, Princeton Instruments, USA) to obtain the scattering spectra. One part of scattered light was collected by a true-color digital camera (Nikon DS-fi, Japan) to obtain the dark-field color images. The other fraction of light was collected by a spectrometer to obtain single particle scattering spectra. ${ }^{36}$ At first, the scattering spectra of single nanorod assembled with trace CTAB was captured in water as the initial scattering spectra. An aqueous solution $(50 \mathrm{~mL})$ comprising $1 \mathrm{mM} \mathrm{CTAB}$ and $0.85 \mathrm{mg} \mathrm{HAuCl}_{4}$ were mixed as the micellar solution. Time-dependent changes in the dark-field image of gold nanoparticles were recorded continuously to monitor the transverse etching reaction. Spectra was integrated 
over $10 \mathrm{~s}$ and calculated by the subtraction between the original response curve spectra and the background spectra of adjacent regions.

\section{Preparation of GNR-functionalized slides}

Indium-tin oxide (ITO) slides were cleaned in an ultrasonic bath using ethanol, acetone and water, respectively. Each sonication step was performed for more than one hour. After sonication, the slides were rinsed with water and dried under a stream of nitrogen prior to immobilization of the GNRs.

\section{Preparation of gold nanodumbbells}

First gold nanorods were immobilized on an ITO slide via the immersion of the as-recieved solution, containing trace levels of $\mathrm{CTAB}$, for $2 \mathrm{~min}$. After carefully rinsing with water, the gold nanoparticles modified substrate was immersed in an aqueous solution of cysteine or gluthathione $(0.1 \mathrm{mM}$ unless stated otherwise) and allowed to react at room temperature for $5 \mathrm{~min}$. After further rinsing in water, a droplet of a micellar solution of CTAB $(1 \mathrm{mM})$ containing $\mathrm{HAuCl}_{4}(0.05 \mathrm{mM})$ was placed onto the substrate. The droplet was allowed to react on the surface for 40 min unless stated otherwise.

\section{Conclusion}

In summary, we designed a novel selective localized reaction to real-time track the morphological variations of single GNRs. Under the calculation methodology, we proposed the mechanism of transverse etching process, which could be used to simulate the single GNRs morphological variations. The experimental results suggested that the selectivity etching could induce the transverse reaction and the cylinder formed dicircular truncated cones. The morphological variations of GNRs could be converted into the scattering light peak under the relationship between the change in aspect ratio and the plasmon resonance scattering peak shifts. The calculation offered a new way to determine and measure the mechanism of morphological variations.

\section{Acknowledgements}

This research was supported by 973 Program (2013CB733700), National Science Fund for Distinguished Young Scholars (21125522), and the National Natural Science Foundation of China $(21327807,21421004)$. Y.-T. Long thanks the support by Shanghai Science and Technology Committee(12JC1403500) and Eastern Scholar at Shanghai Institutions of Higher Learning.

\section{Notes and references}

a Key Laboratory for Advanced Materials \& Department of Chemistry, East China University of Science and Technology, Shanghai 200237, P. R. China. E-mail: ytlong@ecust.edu.cn; Tel/Fax:+86-21-64250032.

b Department of Chemistry, The University of Western Ontario, 1151 Richmond Street, London, ON, Canada N6A 5B7.

${ }^{\mathrm{C}}$ Department of Chemistry, University of Bath, Bath BA2 7AY UK. $\dagger$ Electronic Supplementary Information (ESI) available: Calculation methodology of transverse etching of single gold nanoparticle, UV-vis spectra of GNRs solution, and absorbance changes of the UVspectrophotometry. See DOI: 10.1039/b000000x/

1. F.-R. Fan, D.-Y. Liu, Y.-F. Wu, S. Duan, Z.-X. Xie, Z.-Y. Jiang and Z.-Q. Tian, J. Am. Chem. Soc., 2008, 130, 6949-6951.

2. Y. Sun and Y. Xia, Science, 2002, 298, 2176-2179.

3. M. R. Langille, M. L. Personick, J. Zhang and C. A. Mirkin, J. Am. Chem. Soc., 2012, 134, 14542-14554.

4. M. Grzelczak, A. Sánchez - Iglesias, B. Rodríguez - González, R. Alvarez - Puebla, J. Pérez - Juste and L. M. Liz - Marzán, Adv. Funct. Mater., 2008, 18, 3780-3786.

5. S. J. Hurst, E. K. Payne, L. Qin and C. A. Mirkin, Angew. Chem. Int. Ed., 2006, 45, 2672-2692.

6. R. Jin, Y. Cao, C. A. Mirkin, K. Kelly, G. C. Schatz and J. Zheng, Science, 2001, 294, 1901-1903.

7. J. E. Millstone, S. Park, K. L. Shuford, L. Qin, G. C. Schatz and C. A. Mirkin, J. Am. Chem. Soc., 2005, 127, 5312-5313.

8. J. E. Millstone, S. J. Hurst, G. S. Métraux, J. I. Cutler and C. A. Mirkin, Small, 2009, 5, 646-664.

9. A. R. Tao, S. Habas and P. Yang, Small, 2008, 4, 310-325.

10. H. Yoo, J. E. Millstone, S. Li, J.-W. Jang, W. Wei, J. Wu, G. C. Schatz and C. A. Mirkin, Nano Lett., 2009, 9, 3038-3041.

11. J. Zhang, S. Li, J. Wu, G. C. Schatz and C. A. Mirkin, Angew. Chem., 2009, 121, 7927-7931.

12. H. Chen, L. Shao, Q. Li and J. Wang, Chem. Soc. Rev., 2013, 42, 2679-2724.

13. Y. Xia, Y. Xiong, B. Lim and S. E. Skrabalak, Angew. Chem. Int. Ed., 2009, 48, 60-103.

14. M. R. Jones, K. D. Osberg, R. J. Macfarlane, M. R. Langille and C. A. Mirkin, Chem. Rev., 2011, 111, 3736-3827.

15. J. E. Millstone, W. Wei, M. R. Jones, H. Yoo and C. A. Mirkin, Nano Lett., 2008, 8, 2526-2529.

16. M. Liu and P. Guyot-Sionnest, J. Phys. Chem. B, 2005, 109, $22192-$ 22200.

17. M. L. Personick, M. R. Langille, J. Zhang and C. A. Mirkin, Nano Lett., 2011, 11, 3394-3398.

18. N. Garg, C. Scholl, A. Mohanty and R. Jin, Langmuir, 2010, 26, 10271-10276.

19. P. J. Chung, L. M. Lyu and M. H. Huang, Chem. Eur. J., 2011, 17, 9746-9752.

20. C. J. Murphy, L. B. Thompson, D. J. Chernak, J. A. Yang, S. T. Sivapalan, S. P. Boulos, J. Huang, A. M. Alkilany and P. N. Sisco, Curr. Opin. Colloid Interface Sci., 2011, 16, 128-134.

21. J. R. Navarro, D. Manchon, F. Lerouge, E. Cottancin, J. Lermé, C. Bonnet, F. Chaput, A. Mosset, M. Pellarin and S. Parola, Nanotechnology, 2012, 23, 145707.

22. X. Kou, S. Zhang, Z. Yang, C.-K. Tsung, G. D. Stucky, L. Sun, J. Wang and C. Yan, J. Am. Chem. Soc., 2007, 129, 6402-6404.

23. B. Nikoobakht and M. A. El-Sayed, Chem. Mater., 2003, 15, $1957-$ 1962.

24. T. K. Sau and C. J. Murphy, J. Am. Chem. Soc., 2004, 126, 86488649.

25. N. R. Jana, L. Gearheart and C. J. Murphy, Adv. Mater., 2001, 13, 1389. 
26. J. Rodríguez-Fernández, J. Pérez-Juste, P. Mulvaney and L. M. LizMarzán, J. Phys. Chem. B, 2005, 109, 14257-14261.

27. M. Grzelczak, J. Pérez-Juste, P. Mulvaney and L. M. Liz-Marzán, Chem. Soc. Rev., 2008, 37, 1783-1791.

28. Y. Yu, Q. Zhang, X. Lu and J. Y. Lee, J. Phys. Chem. C, 2010, 114, 11119-11126.

29. W. Niu, S. Zheng, D. Wang, X. Liu, H. Li, S. Han, J. Chen, Z. Tang and G. Xu, J. Am. Chem. Soc., 2008, 131, 697-703.

30. C. Bullen, P. Zijlstra, E. Bakker, M. Gu and C. Raston, Cryst. Growth Des., 2011, 11, 3375-3380.

31. Z. Lin, J. Cai, L. Scriven and H. Davis, J. Phys. Chem., 1994, 98, 5984-5993.

32. B. Nikoobakht and M. A. El-Sayed, Langmuir, 2001, 17, 6368-6374.

33. P. Sudeep, S. S. Joseph and K. G. Thomas, J. Am. Chem. Soc., 2005, 127, 6516-6517.

34. S. Zhang, X. Kou, Z. Yang, Q. Shi, G. D. Stucky, L. Sun, J. Wang and C. Yan, Chem. Commun., 2007, 1816-1818.

35. M. Vollmer and U. Kreibig, Springer Ser. Mat. Sci, 1995, 25.

36. L. Zhang, Y. Li, D. W. Li, C. Jing, X. Chen, M. Lv, Q. Huang, Y. T. Long and I. Willner, Angew. Chem., 2011, 123, 6921-6924. 